\title{
1 Guiding coral reef futures in the Anthropocene
}

2

3

4 Norström A.V. ${ }^{1}$, Nyström M. ${ }^{1}$, Jouffray J-B. ${ }^{1,2}$, Folke C. ${ }^{1,2,3}$, Graham N. A. J. ${ }^{4,5}$,

5 Moberg $\mathrm{F}^{1}$, Olsson $\mathrm{P}^{1}$., Williams G. J. ${ }^{6,7}$

6

7

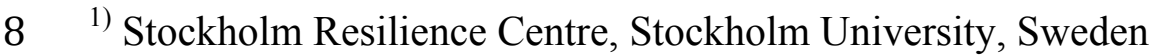

$9{ }^{2)}$ Global Economic Dynamics and the Biosphere Family Erling-Persson Academy

10 Programme, Royal Swedish Academy of Sciences, Sweden

$11{ }^{3)}$ The Beijer Institute, Royal Swedish Academy of Sciences, Sweden

$12{ }^{4)}$ Lancaster Environment Centre, Lancaster University, Lancaster, LA2 9QY, UK

$13{ }^{5)}$ ARC Centre of Excellence for Coral Reef Studies, James Cook University,

14 Australia

$15{ }^{6)}$ Center for Marine Biodiversity \& Conservation, Scripps Institution of

16 Oceanography, La Jolla, CA, USA

$17{ }^{7)}$ School of Ocean Sciences, Bangor University, Anglesey, LL59 5AB, UK 


\section{Abstract}

Human changes to the Earth now rival the great forces of nature, and have shepherded us into a new planetary era - the Anthropocene. Changes include profound, and often surprising, alterations to coral reef ecosystems and the services they provide human societies. Ensuring their future in the Anthropocene will require that key drivers of coral reef change - fishing, water quality and anthropogenic climate change - stay within acceptable levels, or "safe operating spaces". The capacity to remain within these safe operating spaces hinges on understanding the local, but also the increasingly global and cross-scale, socio-economic causes of these human drivers of change. Consequently, even successful local and regional management efforts will fail if current decision making and institution-building around coral reef systems remains fragmented, poorly coordinated, and unable to keep pace with the escalating speed of technological and ecological change in the Anthropocene.

\section{In a nutshell}

- Natural processes that used to shape coral reefs are increasingly being overwhelmed by human impacts.

- Ensuring sustainable coral reef futures in this context will require staying within acceptable levels or "safe operating spaces" of human stressors like fishing, coastal pollution and global warming.

- Defining those safe operating spaces can guide coral reef decision making and institution-building to keep pace with the escalating speed of distal drivers of change, such as trade, human migration and land grabbing.

- This questions current reef ecology paradigms and calls for novel governance approaches to interlinked social, economic and ecological challenges. 
53

54

55

56

57

58

59

60

61

62

63

64

65

66

67

68

69

70

71

72

73

74

75

76

77

78

79

80

81

82

83

84

85

86

87

88

89

90

91

92

93

94

There is growing scientific recognition that we live in the Anthropocene, an era where humans have become a dominant force of planetary change (Steffen et al. 2011).

Changes include profound alterations of the Earth's marine and terrestrial ecosystems and the services they provide to globally interconnected societies and economies (Carpenter et al. 2009). Human migration, international trade, transnational land acquisitions, spread of invasive species and technology diffusion occur at unprecedented scales, underpinned by a global infrastructure that facilitates movement of people, goods, services, diseases and information (Reid et al. 2010). Actions taken in seemingly independent places increasingly affect the interlinked global social-ecological system in unexpected ways, with surprising mixes of immediate consequences as well as cascading and distant effects (Liu et al. 2013).

Coral reefs are informative examples of the key social-ecological challenges and interactions playing out in the Anthropocene. They are economic and social assets that have exhibited stability on centennial to millennial scales, but have experienced an unprecedented decline over the last 50 years (Hughes et al. 2010). Changes to reefs in the Anthropocene are multifaceted and complex. Impacts of overfishing and coastal pollution, which can be managed successfully at local scales, are increasingly compounded by the more recent, superimposed impacts of global warming and ocean acidification. These anthropogenic drivers of change are mediated by underlying traits in the social sphere such as economic systems, demography, cultural dimensions and societal norms. Many coral reefs have already shown signs of transgressing thresholds and have undergone regime shifts to alternate degraded states (Norström et al. 2009). In many cases this is resulting in a reduction of ecosystem services, such as tourism and fisheries that provide income and food security (Moberg and Folke 1999). On the other end of the spectrum, a few reefs are maintained in a semi-pristine state due to their remoteness from direct human impact (Graham and McClanahan 2013). An increasingly common scenario, however, is that reefs change to novel coraldominated ecosystems while still maintaining key functions and ecosystem services at relatively desirable levels (Graham et al. 2014).

The interlinked social, economic and ecological challenges of the Anthropocene call for broader transdisciplinary coral reef science that is complemented by management and governance strategies that facilitate the stewardship of coral reefs. Ecosystem stewardship has emerged as a powerful sustainability framework with a central goal to sustain ecosystem capacity to provide services that support human well-being under conditions of uncertainty and change (Chapin et al. 2010). Here we draw on several areas of emerging transdisciplinary social-ecological research to highlight three broad challenges that need to be addressed in the efforts towards sustainable stewardship of coral reefs. We start by describing safe operating spaces for the key drivers of change that must not be transgressed for coral reefs to continue 
to develop and exist. We then explore some of the critical cross-scale socialecological interactions that will increasingly challenge the capacity to remain within these safe operating spaces, and propose ways to study these social-ecological interconnections. Finally, we outline the governance and institutional $\mathrm{f}$ that need to be in place for navigating coral reefs towards a sustainable future.

\section{Safe operating spaces for global coral reef change}

Avoiding thresholds that trigger regime shifts is becoming a focal point of resiliencebased management of coral reefs. However, despite recent advances in predicting thresholds (Mumby et al. 2007; Graham et al. 2015) their global generalizability is confounded by a strong dependence on the historical, geographic and environmental context of the system. Furthermore, the ecosystem consequences of crossing thresholds may lag by decades (or even centuries) and may not be obvious over human time scales (Hughes et al 2013). In the face of this uncertainty a complementary approach has been to establish safe operating spaces for ecosystems (Scheffer et al. 2015). This concept is distinct from identifying specific thresholds. Safe operating spaces are set to maintain safe levels of human drivers to avoid the long-term degradation of ecosystems, and societies that depend on them. The concept neither assumes, nor rules out, the existence of thresholds and is applicable in situations with different types of system responses to increased levels of different drivers (Hughes et al 2013, Figure 1). We set safe operating spaces and zones of uncertainty for three key drivers threatening coral reef globally; i) fishing ii) water quality, and iii) anthropogenic climate change (i.e. sea surface temperature, aragonite saturation levels, ocean acidification). The safe operating space (green zones in Figure 2) indicates the values of the drivers set at a "safe" distance from potentially dangerous levels or threshold points (where they exist). Defining the safe operating spaces is challenging and involves uncertainty due to interactions among drivers (WebPanel 1), variable responses within and among taxa, geographic variation, data limitation and the scope for acclimation or adaptation of reef-organisms to change (Mumby and Van Woesik 2014; Barkley et al. 2015). Consequently, a zone of uncertainty is associated with each of the drivers (yellow zones in Figure 2). Moving towards the "high risk" (red) zones represents an increasing probability of crossing a critical threshold or accelerating toward a deleterious state (Steffen et al. 2015). The values we provide should be regarded as guidelines that will become more accurate with increasing studies and knowledge.

\section{Fishing}

Historical overfishing precedes all other pervasive human drivers of change on coral reefs (Jackson et al. 2001). As predatory and herbivorous fish are removed from reef ecosystems, the risk of crossing thresholds and undergoing regime shifts to undesirable reef configurations increases. In order to set a safe operating range for fishing, we draw on recent regional (McClanahan et al. 2011, 2015; Karr et al. 2015) and global (MacNeil et al. 2015) assessments of the threshold and non-linear 
141 dynamics associated with fishable biomass - an easily measured proxy of fishing

142 pressure - on reefs. Threshold points in the trend or variance associated with a range

143 of ecosystem processes (e.g. herbivory, predation), state variables (e.g. the ratio of

144 coral to macroalgae cover), fish community life history traits and functional

145 groupings were associated with fishable biomass levels between $25-50 \%$ of unfished

146 biomass (calculated from recovery trajectories in marine reserves, and unfished

147 reference sites in each region). The results of these studies suggest that maintaining

148 reefs in a desirable regime (i.e. low macroalgal cover, high coral cover, high fish

149 diversity) requires fishable biomass to be kept above $500 \mathrm{~kg} \mathrm{ha}^{-1}$, with a zone of

150 uncertainty between $500-250 \mathrm{~kg} \mathrm{ha}^{-1}$ (Figure 1).

151

152

Water quality

153

In many parts of the world, water quality (e.g. nutrient loads, pollutants, sediments) in coastal areas is changing in response to rapid urbanization, increasing fertilizer use and land use change. Poor water quality can disrupt coral reproduction and recruitment, smother adult corals and favor algal proliferation (Fabricius 2005). A representative proxy for overall water quality status, which is highly correlated to nutrient status and phytoplankton biomass, is chlorophyll concentration (De'ath and Fabricius 2010). Although high natural variability in chlorophyll levels occur in some areas (e.g. atolls) (Gove et al. 2016), and can have positive effects on reef productivity (Williams et al. 2015), a large-scale assessment of the relationship between chlorophyll and reef condition across the whole of the Great Barrier Reef in Australia, found critical levels of $0.45 \mu \mathrm{g} \mathrm{L}^{-1}$ chlorophyll beyond which macroalgal cover increased and hard coral richness declined (De'ath and Fabricius 2010). Earlier, smaller-scale, studies from Barbados and Hawaii also showed measurable negative changes at chlorophyll annual means above $0.5 \mu \mathrm{g} \mathrm{L}^{-1}$ (Bell 1992). We therefore suggest a safe-operating space value of chlorophyll concentration below $0.45 \mu \mathrm{g} \mathrm{L}^{-1}$, and a zone of uncertainty between $0.45-0.55 \mu \mathrm{g} \mathrm{L}^{-1}$, for continental and archipelago reef systems (Figure 1).

\section{Anthropogenic climate change}

Human-induced increases in atmospheric $\mathrm{CO}_{2}$ concentrations $\left(\left[\mathrm{CO}_{2}\right]_{\mathrm{atm}}\right)$ have driven rapid rises in sea surface temperatures (SST) and ongoing ocean acidification (OA). The vulnerability of reef-building corals to the unprecedented rates of change in SST has been well documented; when temperatures exceed summer maxima by $1^{\circ}-2^{\circ} \mathrm{C}$ for 3-4 weeks coral bleaching and mortality occurs. It is the increased intensity and frequency of episodes of ocean warming and associated mass bleaching events (i.e. the significant bleaching of multiple coral species at a regional scale) that is compromising the long-term integrity of coral reefs. If mass bleaching events become annual or biennial events corals may experience chronic decline as a result of reduced growth, calcification, fecundity and greater incidences of disease (Hoegh-Guldberg et 
al. 2007). Models suggest that avoiding chronic mass bleaching events (i.e. annual or biennial) for the majority of the world's coral reefs requires keeping [CO2]atm levels below 480 ppm (Donner et al. 2005; Hoegh-Guldberg et al. 2007), or even below 450 ppm (van Hooidonk et al. 2013). However, substantially lower levels of $\left[\mathrm{CO}_{2}\right]_{\text {atm }}$ have been suggested based on conservative backcasting exercises that associate the advent of highly destructive mass bleaching (e.g. the 1997/1998 mass bleaching event which killed approximately $16 \%$ of coral communities globally), with $\left[\mathrm{CO}_{2}\right]_{\text {atm }}$ values of 340 ppm (Veron et al. 2009). We therefore suggest that the safe operating space to avoid chronic mass bleaching ends at $340 \mathrm{ppm}$, with the zone of uncertainty ranging between 340-480 ppm (Figure 1). With a current global value of $400 \mathrm{ppm}$ it means that reefs have already entered the zone of uncertainty.

Absorption of $\mathrm{CO}_{2}$ by the ocean is reducing water $\mathrm{pH}$ and the saturation levels of aragonite $\left(\Omega_{\text {arag }}\right)$, the principle crystalline form of calcium carbonate deposited in coral skeletons. Coral reefs are commonly found in regions with $\Omega_{\text {arag }}$ values greater than 3.3, and this observation underlies projections of global coral reef decline as $\left[\mathrm{CO}_{2}\right]_{\text {atm }}$ approaches $480 \mathrm{ppm}$ and $\Omega_{\text {arag }}$ drops below 3.3 (Hoegh-Guldberg 2010). More recent models, parameterized by field observations of coral community calcification as a response to $\Omega_{\text {arag, }}$, SST and live coral cover values, predict that by the time $\left[\mathrm{CO}_{2}\right]_{\text {atm }}$ will reach $560 \mathrm{ppm}$ almost all coral reefs will cease to grow and start to dissolve (Silverman et al. 2009). However, internal pH up-regulation at the point of calcification has been shown to reduce the vulnerability of corals to ocean acidification, and varies among species (McCulloch et al. 2012). Evidence for changing calcification rates on contemporary reefs is therefore inconclusive (Cooper et al. 2012). Studies from naturally low-pH coral communities suggest that adaptation to low $\mathrm{pH}$ can occur over long time scales (Barkley et al. 2015), but that many ecological properties might be irreversibly damaged as $\mathrm{pH}$ drops below 7.8 at [CO2]atm 750 ppm (Fabricius et al. 2011). Consequently, we set a safe upper boundary associated with ocean acidification at $480 \mathrm{ppm}$, and a broad zone of uncertainty between 480-750 ppm (Figure 1).

\section{Coral reef social-ecological dynamics in the Anthropocene}

The capacity to keep human drivers of change within safe operating spaces is challenged by a broad range of socio-economic interactions and feedbacks between reef systems and the human societies that depend on their goods and services (Panel 1). However, social-ecological dynamics in the Anthropocene are seldom just local or place-specific but rather influenced by multiple global drivers with complex connections to other places that are now more prevalent, and occur more quickly, than ever before (Liu et al. 2013). We highlight three transboundary interactions - trade, human migration and foreign investments in land and large-scale land acquisitions 
(land grabbing) - that will increasingly define coral reef social-ecological dynamics (Figure 3).

Regional and global analyses suggest that access to external markets can affect coral reef fish resources (Cinner et al. 2013). Aside from local consumptive markets, the global aquarium trade targets over 1800 species of reef fishes and removes up to 30 million fish per year (Rhyne et al. 2012), while the live reef fish trade (LRFT) involves the exploitation of coral reef fishes from across the Indo-Pacific to satiate consumer demand in luxury seafood restaurants (Johnston and Yeeting 2006). Similarly, many invertebrate reef fisheries are extensively embedded in global trade networks composed by actors operating at different levels, including local fishers, middlemen and consumers in areas far from the reefs themselves. A consequence of this increased market connectivity and nestedness is that many local invertebrate and reef fish stocks are sequentially depleted as a result of the rapid emergence of specialized export markets and quick spatial shifts in exploitation (Scales et al. 2007; Eriksson et al. 2015).

Human migration, in particular to coastal regions, is currently at unprecedented levels (Ozden et al. 2011) and forecast to increase as a response to the socialecological changes associated with the Anthropocene. Consequently, local socialecological dynamics will increasingly be sculpted by the complex flows of people across and within administrative boundaries. Fishers associated with coral reefs are already highly mobile in many regions and known to move to areas where the fish are more easily caught (Pollnac et al. 2010). Coastal areas are often the targets for internal migration in many countries, particularly as urban centers and industries promising employment are commonly located at the coast. While mobility can be a key strategy for coastal communities to cope with global change, it can also exacerbate reef resource degradation through the concentration of fishing effort, introduction of new technology and fishing gear, and the deterioration of traditional rules and practices (Cassels et al. 2005).

A third important cluster of drivers are foreign investments in land and largescale land acquisitions - commonly referred to as land grabbing - that are increasingly driving land use change (Meyfroidt et al. 2013). Land use change is a substantial threat to coral reefs, by directly affecting sediment, pollution and fresh water discharge into coastal zones. Past examples show how large-scale land clearing driven by intensive banana production, and exasperated by tourism development, has depleted coral communities in certain Caribbean reefs (Cramer et al. 2012). More recent modeling efforts are suggesting that human deforestation, primarily driven by demand for agricultural land, mineral exploration and mining, will outweigh climate change as the principal contributor to increased sedimentation of near-shore marine environments in Madagascar (Maina et al. 2013). Similarly, the run-off from export agriculture such as squash in Tonga and oil palm in Papua New Guinea is emerging as a key driver of change in Pacific Island reefs (Hunt 2003). 
Capturing and studying the growing importance of these complex socialecological interconnections on coral reef systems is a key research challenge.

Research on land systems change has made progress, from which coral reef socialecological systems research could learn. For example, cross-country statistical analyses have shown that recent tropical deforestation is associated with international trade of agricultural products and remote urban demand, rather than with rural population growth (DeFries et al. 2010). This resonates with coral reef systems, where access to markets (e.g. for exports or satisfying urban demand) is often a better predictor of overall reef fish biomass than other local socio-economic and natural drivers (Cinner et al. 2013). Land systems change research has also explored "displacement" and "cascade effects" - the unintended negative consequences of forest recovery beyond the borders of reforesting countries. For example, recent forest transitions and forest protection policies in both developed and developing countries have outsourced forest exploitation abroad via increased imports of wood and agricultural products (Meyfroidt et al. 2013). Such approaches merge detailed economic (forest product prices, imports and exports of wood products) and environmental (land cover change) data. Similar analyses could be used to investigate whether the positive relationship between socio-economic development and reef condition in some parts of the world is due to displacement of domestic environment impacts through trade, or because of other, local factors such as low dependence on fishing and reduced use of potentially damaging gear (Cinner et al. 2009a). Similarly, while Marine Protected Areas (MPAs) can displace fishing effort at a local scale, the potential leakage of fishing effort across regions and national borders is a key research gap - especially in light of current trends of establishing large mega-reserves in many regions (Graham and McClanahan 2013). More recently the framework of telecoupling is allowing for increasingly integrated analyses of the central flows (material, people, energy and information) between social-ecological systems and their causes and effects (Liu et al. 2013). The approaches to analyze cross-scale linkages in coral reef social-ecological systems will be determined by the specific context, research question and data available. Learning from other disciplines and adapting existing methods and frameworks will speed these advances.

\section{Stewardship of coral reefs: governance at multiple scales}

Conventional approaches to deal with the decline of coral reefs, such as MPAs can offer local socioeconomic and ecological benefits but are usually narrow in scope, small-scale and often suffer from weak compliance and enforcement (Pollnac et al. 2010). Coral reef management is slowly shifting towards more systemic management strategies that are collaborative (involving both state and non-state actors) and adaptive, focus on ecosystem processes underpinning resilience and target socialecological interactions across the wider seascape (Panel 1). Advancing socialecological and adaptive comanagement approaches requires acknowledging the 
broader social, governance and institutional (norms and rules) contexts that enable their successful implementation. For example, while monitoring and experimentation are central tenets of adaptively managing coral reefs, they have typically been carried out by specialists. Involving local resource users in the monitoring process enhances incentives to learn about local ecosystem dynamics and facilitates collective action in line with the management objectives (Christie et al. 2009; Montambault et al. 2015). Initial support by local communities and government bodies is crucial (Olsson et al. 2004), and hinges on the management plans building on existing rules and institutions, such as traditional tenure and community committees. Research on social-ecological transformations has also highlighted the role of key individuals that foster trust and build partnerships between stakeholders (e.g., community groups, religious leaders, government authorities, NGOs and researchers) and facilitate the participatory and inclusive process that sets and adapts the management strategies to local contexts (Schultz et al. 2015).

However, local management efforts alone will not be able to keep pace with the escalating speed of technological and ecological change in the Anthropocene. An international binding treaty to alleviate coral reef degradation has not materialized, despite a number of favorable factors, such as the presence of supporting business interests, public appeal and the relatively small number of nations involved (Dimitrov 2002). However, the socio-economic and environmental issues facing marine ecosystems are finally receiving a focus equal to their terrestrial counterparts. For example, Goal 14 of the newly adopted United Nations Sustainable Development Goals encompasses ten targets for sustainable development in the oceans, while one of Convention of Biological Diversity's Aichi Targets explicitly calls to minimize anthropogenic pressures on coral reefs and maintain their integrity and functioning. This momentum could provide a window of opportunity for organizations such as the International Coral Reef Initiative (ICRI) and the International Society for Reef Studies (ISRS) to more ambitiously engage with high-level policy processes across different sectors, such as climate change and trade, and bring issues of coral reef sustainability on the negotiating tables. Crucially, it will require strategic collaborations with emerging regional management initiatives such as the Micronesia Challenge, the Caribbean Challenge Initiative, Western Indian Ocean Coastal Challenge and Coral Triangle Initiative. These serve as practical operating platforms convening political leaders, non-governmental organizations, coastal communities and scientists to sustainably manage marine and coastal resources (Rosen and Olsson 2013; Johnson et al. 2014). This type of multi-level governance systems involving state and non-state actors have emerged in response to other complex transnational and regional collective action problems such as ocean acidification (Galaz et al. 2012) and fisheries overexploitation (Österblom and Sumaila 2011) when enforceable global agreements are missing or have failed. Importantly, it has been shown that they foster learning between several types of individuals and organizations, nurture trust and can facilitate collective action toward common goals. 


\section{Conclusions}

358

359

360

361

362

363

364

365

366

367

368

369

370

371

372

373

374

375

376

377

378

379

380

381

382

383

384

Ensuring sustainable coral reef futures in the Anthropocene will require human drivers of change to stay within safe levels, far from dangerous thresholds. Local and regional actions can enhance resilience and limit the longer-term damage from climate-related effects by keeping fishing and water quality targets within their safe operating spaces. It is critical that such management targets are applied within a broader adaptive management context, which allows for learning and experimentation, and tolerates variability within the safe operating spaces. Management strategies that reduce the short-term variance near the boundary levels run the risk of narrowing the safe operating space, with potentially catastrophic consequences (Carpenter et al. 2015). Understanding the social dynamics underlying these drivers of change becomes crucial. New research is required to better understand how social-ecological dynamics are affected by interactions between regions, and across large distances. These insights call for developing governance systems that foster international and cross-sectorial cooperation to address the sustainability challenges of an increasingly interconnected world. We reinforce the urgency for coral reef science to deeply engage with emerging regional management initiatives (such as the Micronesia Challenge and Coral Triangle Initiative) and the international policy arena (such as the United Nations Framework Convention on Climate Change) to work for sharp reductions of greenhouse gas emissions and the implementation of the Sustainable Development Goals. In 2016, the 13th international coral reef symposium (ICRS) will bring together an anticipated 2,500 coral reef scientists, policy makers and managers from 70 different nations under the theme of "Bridging Science to Policy". It is time for this broad community to collectively step up to the plate and help steer reefs toward a more sustainable future.

\section{Panel 1. Social-ecological research on coral reefs}

Coral reef social-ecological systems (SES) research has grown exponentially over the past 25 years (Figure 2), with a strong emphasis at the local or regional scale. One sub-set of coral SES research has focused on ecosystem services and human wellbeing in tropical coastal communities that exhibit livelihood strategies that are strongly tied to coral reefs. Ecosystem services associated with coral reefs extend beyond food production and encompass a broad bundle of provisioning, regulating and cultural services that varies across regions and contexts (Moberg and Folke 1999). Novel insights are uncovering how different social, institutional and knowledge mechanisms determine access to these different ecosystem services, and how preferences for ecosystem services are linked to inherent psychological values held by 

different kinds of people (Hicks and Cinner 2014; Hicks et al. 2015). Another sub-set of this research has highlighted how the combination of weak or missing institutions, a lack of individual and institutional leadership, few alternative livelihoods and inadequate financial capacity can trap a coral reef SES in undesirable and unsustainable pathways (Cinner 2011; Sale et al. 2014). Finally, a third broad category of research is using different diagnostic SES frameworks to understand how the ecological performance of fisheries and marine reserves is related to different socioeconomic variables of associated coastal communities (Pollnac et al. 2010).

This body of research is also beginning to underlie novel approaches to management that specifically include the local human communities dependent on coral reefs. For example, different fisheries management tools (such as gear-based management and size-selectivity) can help to maintain key ecosystem functions and significant yields of provisioning and other services (Johnson 2010). The emergence of property rights systems for coral reef fisheries, such as Kenya's recent Beach Management Unit legislation, allows local communities to deal with transgressions committed by outside poachers or globalized "roving-bandit" type exploitation (Cinner et al. 2009b). Combining local knowledge with contemporary science is developing 'hybrid' co-management systems that are having tangible conservation benefits (Aswani et al. 2012). Finally, there are increased calls for adaptive management efforts that emphasize collaborative "management experiments" and the importance of learning from these experiments. For example, viewing the implementation of MPAs as a hypothesis driven process that is monitored would enable managers to learn what works and better anticipate the uncertain futures of coral reefs.

\section{References}

Aswani S, Christie P, Muthiga NA, et al. 2012. The way forward with ecosystembased management in tropical contexts: reconciling with existing management systems. Mar Policy 36: 1-10.

Barkley HC, Cohen AL, Golbuu Y, et al. 2015. Changes in coral reef communities across a natural gradient in seawater pH. Sci Adv 1: e1500328.

Bell P. 1992. Eutrophication and coral reefs: examples in the Great Barrier Reef lagoon. Water Res 26: 553-68.

Carpenter SR, Mooney HA, Agard J, et al. 2009. Science for managing ecosystem services: Beyond the Millennium Ecosystem Assessment. Proc Natl Acad Sci 106: $1305-12$.

Cassels S, Curran SR, and Kramer R. 2005. Do migrants degrade coastal 
environments? Migration, natural resource extraction and poverty in North Sulawesi, Indonesia. Hum Ecol 33: 329-63.

Chapin FS, Carpenter SR, Kofinas GP, et al. 2010. Ecosystem stewardship: sustainability strategies for a rapidly changing planet. Trends Ecol Evol 25: 2419.

Christie P, Pollnac RB, Fluharty DL, et al. 2009. Tropical Marine EBM Feasibility: A Synthesis of Case Studies and Comparative Analyses. Coast Manag 37: 374-85.

Cinner JE. 2011. Social-ecological traps in reef fisheries. Glob Environ Chang 21: 835-9.

Cinner JE, Graham NAJ, Huchery C, and MacNeil MA. 2013. Global effects of local human population density and distance to markets on the condition of coral reef fisheries. Conserv Biol 27: 453-8.

Cinner JE, McClanahan TR, Daw TM, et al. 2009a. Linking social and ecological systems to sustain coral reef fisheries. Curr Biol 19: 206-12.

Cinner JE, Wamukota A, Randriamahazo H, and Rabearisoa A. 2009b. Toward institutions for community-based management of inshore marine resources in the Western Indian Ocean. Mar Policy 33: 489-96.

Cooper TF, O'Leary RA, and Lough JM. 2012. Growth of Western Australian corals in the anthropocene. Science 335: 593-6.

Cramer KL, Jackson JBC, Angioletti C V, et al. 2012. Anthropogenic mortality on coral reefs in Caribbean Panama predates coral disease and bleaching. Ecol Lett 15: $561-7$.

De'ath $\mathrm{G}$ and Fabricius K. 2010. Water quality as a regional driver of coral biodiversity and macroalgae on the Great Barrier Reef. Ecol Appl 20: 840-50.

DeFries RS, Rudel T, Uriarte M, and Hansen M. 2010. Deforestation driven by urban population growth and agricultural trade in the twenty-first century. Nat Geosci 3: $178-81$.

Dimitrov RS. 2002. Confronting nonregimes: science and international coral reef policy. J Environ Dev 11: 53-78.

Donner SD, Skirving WJ, Little CM, et al. 2005. Global assessment of coral bleaching and required rates of adaptation under climate change. Glob Chang Biol 11: 2251-65.

Eriksson H, Österblom H, Crona B, et al. 2015. Contagious exploitation of marine resources. Front Ecol Environ 13: 435-40.

Fabricius K. 2005. Effects of terrestrial runoff on the ecology of corals and coral reefs: review and synthesis. Mar Pollut Bull 50: 125-46. 
Fabricius KE, Langdon C, Uthicke S, et al. 2011. Losers and winners in coral reefs acclimatized to elevated carbon dioxide concentrations. Nat Clim Chang 1: 1659.

Galaz V, Crona B, Österblom H, et al. 2012. Polycentric systems and interacting planetary boundaries - Emerging governance of climate change-ocean acidification-marine biodiversity. Ecol Econ 81: 21-32.

Gove JM, McManus MA, Neuheimer AB, et al. 2016 Near-island biological hotspots in barren ocean basins. Nat Commun 7: 10581.

Graham NA, Cinner JE, Norström A V, and Nyström M. 2014. Coral reefs as novel ecosystems: embracing new futures. Curr Opin Environ Sustain 7: 9-14.

Graham NAJ, Jennings S, Macneil MA, et al. 2015. Predicting climate-driven regime shifts versus rebound potential in coral reefs. Nature 518: 94-7.

Graham NAJ and McClanahan TR. 2013. The last call for marine wilderness? Bioscience 63: 397-402.

Hicks CC and Cinner JE. 2014. Social, institutional, and knowledge mechanisms mediate diverse ecosystem service benefits from coral reefs. Proc Natl Acad Sci 111: $17791-6$.

Hicks CC, Cinner JE, Stoeckl N, and McClanahan TR. 2015. Linking ecosystem services and human-values theory. Conserv Biol 29: 1471-80.

Hoegh-Guldberg O. 2010. Coral reef ecosystems and anthropogenic climate change. Reg Environ Chang 11: 215-27.

Hoegh-Guldberg O, Mumby PJ, Hooten AJ, et al. 2007. Coral reefs under rapid climate change and ocean acidification. Science 318: 1737-42.

Hooidonk R van, Maynard J, and Planes S. 2013. Temporary refugia for coral reefs in a warming world. Nat Clim Chang 3: 508-11.

Hughes TP, Graham NAJ, Jackson JBC, et al. 2010. Rising to the challenge of sustaining coral reef resilience. Trends Ecol Evol 25: 633-42.

Hughes TP, Carpenter S, Rockström J, et al. 2013. Multiscale regime shifts and planetary boundaries. Trends Ecol Evol 28: 389-95

Hunt C. 2003. Economic globalisation impacts on Pacific marine resources. Mar Policy 27: 79-85.

Jackson JBC, Kirby MX, Berger WH, et al. 2001. Historical overfishing and the recent collapse of coastal ecosystems. Science 293: 629-38.

Johnson AE. 2010. Reducing bycatch in coral reef trap fisheries: Escape gaps as a step towards sustainability. Mar Ecol Prog Ser 415: 201-9. 
Johnson DE, Martinez C, Vestergaard O, et al. 2014. Building the regional perspective: Platforms for success. Aquat Conserv Mar Freshw Ecosyst 24: 7593.

Johnston B and Yeeting B. 2006. Economics and marketing of the live reef fish trade in Asia-Pacific.

Karr KA, Fujita R, Halpern BS, et al. 2015. Thresholds in Caribbean coral reefs: implications for ecosystem-based fishery management. J Appl Ecol 52: 402-12.

Liu J, Hull V, Batistella M, et al. 2013. Framing Sustainability in a Telecoupled World. Ecol Soc 18.

MacNeil MA, Graham N a. J, Cinner JE, et al. 2015. Recovery potential of the world's coral reef fishes. Nature 520: 341-4.

Maina J, Moel H de, Zinke J, et al. 2013. Human deforestation outweighs future climate change impacts of sedimentation on coral reefs. Nat Commun 4: 1986.

McClanahan TR, Graham NAJ, MacNeil MA, et al. 2011. Critical thresholds and tangible targets for ecosystem-based management of coral reef fisheries. Proc Natl Acad Sci U S A 108: 17230-3.

McClanahan TR, Graham NAJ, MacNeil MA, and Cinner JE. 2015. Biomass-based targets and the management of multispecies coral reef fisheries. Conserv Biol 29: 409-17.

McCulloch M, Falter J, Trotter J, and Montagna P. 2012. Coral resilience to ocean acidification and global warming through $\mathrm{pH}$ up-regulation. Nat Clim Chang 2: $623-7$.

Meyfroidt P, Lambin EF, Erb K-H, and Hertel TW. 2013. Globalization of land use: distant drivers of land change and geographic displacement of land use. Curr Opin Environ Sustain 5: 438-44.

Moberg F and Folke C. 1999. Ecological goods and services of coral reef ecosystems. Ecol Econ 29: 215-33.

Montambault JR, Wongbusarakum S, Leberer T, et al. 2015. Use of monitoring data to support conservation management and policy decisions in Micronesia. Conserv Biol 29: 1279-89.

Mumby PJ, Hastings A, and Edwards HJ. 2007. Thresholds and the resilience of Caribbean coral reefs. Nature 450: 98-101.

Mumby PJ and Woesik R Van. 2014. Consequences of ecological, evolutionary and biogeochemical uncertainty for coral reef responses to climatic stress. Curr Biol 24: R413-23.

Norström A, Nyström M, Lokrantz J, and Folke C. 2009. Alternative states on coral 
reefs: beyond coral-macroalgal phase shifts. Mar Ecol Prog Ser 376: 295-306.

Olsson P, Folke C, and Berkes F. 2004. Adaptive comanagement for building resilience in social-ecological systems. Environ Manage 34: 75-90.

Österblom H and Sumaila UR. 2011. Toothfish crises, actor diversity and the emergence of compliance mechanisms in the Southern Ocean. Glob Environ Chang 21: 972-82.

Ozden C, Parsons CR, Schiff M, and Walmsley TL. 2011. Where on Earth is everybody? The evolution of global bilateral migration 1960-2000. World Bank Econ Rev 25: 12-56.

Pollnac R, Christie P, Cinner JE, et al. 2010. Marine reserves as linked socialecological systems. Proc Natl Acad Sci U S A 107: 18262-5.

Reid W V., Chen D, Goldfarb L, et al. 2010. Earth system science for global sustainability: grand challenges. Science 330: 916-7.

Rhyne AL, Tlusty MF, Schofield PJ, et al. 2012. Revealing the appetite of the marine aquarium fish trade: the volume and biodiversity of fish imported into the United States. PLoS One 7: e35808.

Sale PF, Agardy T, Ainsworth CH, et al. 2014. Transforming management of tropical coastal seas to cope with challenges of the 21st century. Mar Pollut Bull 85: 823.

Scales H, Balmford A, and Manica A. 2007. Impacts of the live reef fish trade on populations of coral reef fish off northern Borneo. Proc Biol Sci 274: 989-94.

Scheffer BM, Barrett S, Folke C, et al. 2015. Creating a safe operating space for iconic ecosystems. Science 347: 1317-9.

Silverman J, Lazar B, Cao L, et al. 2009. Coral reefs may start dissolving when atmospheric CO 2 doubles. Geophys Res Lett 36: L05606.

Steffen W, Persson $\AA$, Deutsch L, et al. 2011. The Anthropocene: from global change to planetary stewardship. Ambio 40: 739-61.

Steffen W, Richardson K, Rockstrom J, et al. 2015. Planetary boundaries: guiding human development on a changing planet. Science 347: 1259855.

Veron JEN, Hoegh-Guldberg O, Lenton TM, et al. 2009. The coral reef crisis: the critical importance of $<350$ ppm CO2. Mar Pollut Bull 58: 1428-36.

Williams GJ, Gove JM, Eynaud Y, et al. 2015. Local human impacts decouple natural biophysical relationships on Pacific coral reefs. Ecography 38: 751-61. 
580 Figure 1. Three potential ways a coral reef may respond to increased driver levels are

581 illustrated, and all three are congruent with the safe operating space concept.

582 Increased levels of certain drivers (e.g. overfishing) may trigger threshold responses (I 583 and II). For other drivers the response, as far as we know, is a smoother acceleration 584 towards a deleterious state (III). The safe operating space (green zones) indicates the 585 range of driver values that are at a "safe" distance from potentially dangerous levels 586 or threshold points. The zone of uncertainty associated with each of the boundaries 587 (yellow zones) encapsulates the gaps in scientific knowledge and uncertainty due to 588 driver interaction, scope for adaptation and geographic variation. As driver values 589 move towards the "high risk" end of the zone of uncertainty, there is an increasing 590 probability of crossing a critical threshold or accelerating toward a deleterious state. 591 Modified from Rockström et al. 2009 and Hughes et al. 2013

592 Figure 2. The safe operating spaces, zones of uncertainty and zones of high risk of 593 the key drivers of change on coral reefs; i) fishing ii) water quality, and iii) 594 anthropogenic climate change (i.e. sea surface temperature and ocean acidification).

595 Figure 3 (to be embedded in Panel 2). The dramatic increase of coral reef social596 ecological research. An ISI Web of Knowledge literature survey showed that the 597 number of papers containing the keywords "coral reef" together with either "social598 ecological", "socio-ecological", "social-environmental" or "socio-environmental" has 599 increased exponentially between $1990(n=1)$ and $2014(n=106)$.

600 Figure 4. Three global interactions that shape local social-ecological dynamics of 601 coral reefs: 1) Human migration to coastal areas can result in deterioration of 602 traditional rules and practices, enhance pollution and increase pressures on reef fish 603 stocks. Graph shows net global migration to coastal areas between 1970-2010, and 604 specifically in the regions housing the majority of the worlds coral reefs; 2) Land 605 grabbing is increasingly driving land use change, which is a threat to coral reefs by 606 directly affecting water quality (e.g. nutrient loads, pollutants, sediments). Graph 607 shows cumulative number of concluded land grab deals between 2000-2014 on a 608 global scale, and in countries that have coral reefs; 3) International trade of coral reef 609 products is driven by intensifying foreign consumer demand and better access to 610 markets. Graph shows US imports of chilled reef fish (groupers and snappers) and 611 live coral colonies between 1990-2014. Data sources and methods are explained in 612 WebPanel 2. 